\title{
Automatic Ventilation and Air Conditioning System for Educational Training
}

\author{
Ionel Laurentiu Alboteanu*, Andrei Cosmin Militaru ${ }^{\dagger}$ \\ * University of Craiova / Department of Electromechanical, Environmental and Applied Informatics, Craiova, \\ Romania, e-mail: lalboteanu@em.ucv.ro \\ ${ }^{\dagger}$ SC ELPREST SRL/Technical-commercial department Craiova, Romania, e-mail: andreicosminmilitaru1@gmail.com
}

\section{DOI: 10.52846/AUCEE.2021.1.08}

\begin{abstract}
The air quality from closed spaces is very important for people or for technological processes. The heating, ventilation and air conditioning installations ensure the maintenance of the air parameters in the rooms served within pre-established limits, throughout the year, regardless of the variation of meteorological factors, the degree of occupancy of the rooms or the development of production processes. The paper presents an automatic ventilation, heating and air conditioning system made on a small scale. Climatic parameters can be monitored and controlled in two ways: in local mode and also in remote mode. In local mode, the control of the installation is done with a Mega 2560 development system made around the Atmega 2560 microcontroller, which processes the information received from the DHT22 temperature and humidity sensor. Information about parameters and system status is displayed on the local screen. The WeMos D1 R2 WiFi development system based on an ESP8266 wireless microcontroller with Wi-Fi 802.11 compatible with the IDE-Arduino development environment was used for the remote control. All information is transmitted wirelessly to an online platform, called Cayene that allows their storage and control. The platform referred to offers a number of graphical features that do not involve costs for users. The system can be used both for educational purposes for engineering students, but can be adapted for real practical applications.
\end{abstract}

Cuvinte cheie: sistem de incalzire ventilare si climatizare, monitorizate, microcontroler, senzori, temperatura, umiditate.
Keywords: heating, ventilation and air conditioning system (HVAC), monitoring, microcontroller, sensor, temperature, humidity.

\section{INTRODUCTION}

The room air may occur a number of pollutants from the occupants (carbon dioxide resulting from respiration, cigarette smoke, etc.), building materials (gases, vapors) or the process of manufacture (e.g. : solvents).

Air conditioning is the technique that consists in modifying, controlling and regulating the climatic conditions (temperature, humidity, etc.) of the room for various reasons: comfort (individual homes, small spaces), requirements imposed by various factors or for technical reasons (eg: electronic component production facilities, spaces for the production of automobiles, engines, medical laboratories, theaters of operations, rooms where computer servers are located, etc.) [1], [2]. Modern techniques and equipment are currently being used to increase the efficiency of HVAC systems [3].

\section{Structure of HeAting Ventilation AND Air CONDITIONING SYSTEM}

The role of the ventilation system is to eliminate or dilute the harmful substances below the danger limit for the human body, by introducing fresh air and evacuating the contaminated air.

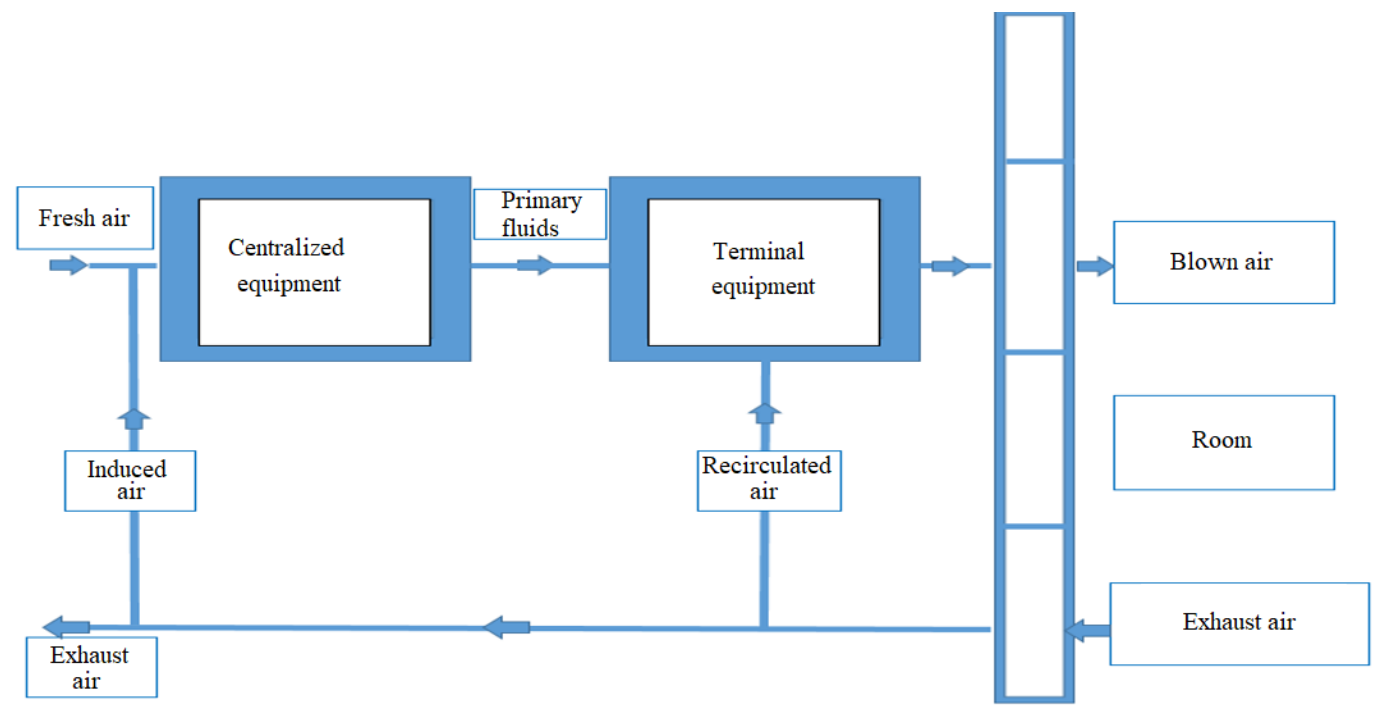

Fig.1. Block diagram of a heating, ventilation and air conditioning system 
If, in addition to the requirements on air purity, it is necessary to ensure certain temperature and humidity parameters for the room air, the ventilation installation is transformed into an air conditioning installation (fig 1.) [4].

A heating, humidification and ventilation installation forms a central air conditioning installation and is made up of a set of equipment having the following functions [5] (fig.2):

- air preparation and distribution with well-defined thermal, aeraulic and acoustic characteristics;

- distribution of treated air in places with air conditioners through intermediate pipes and terminal devices

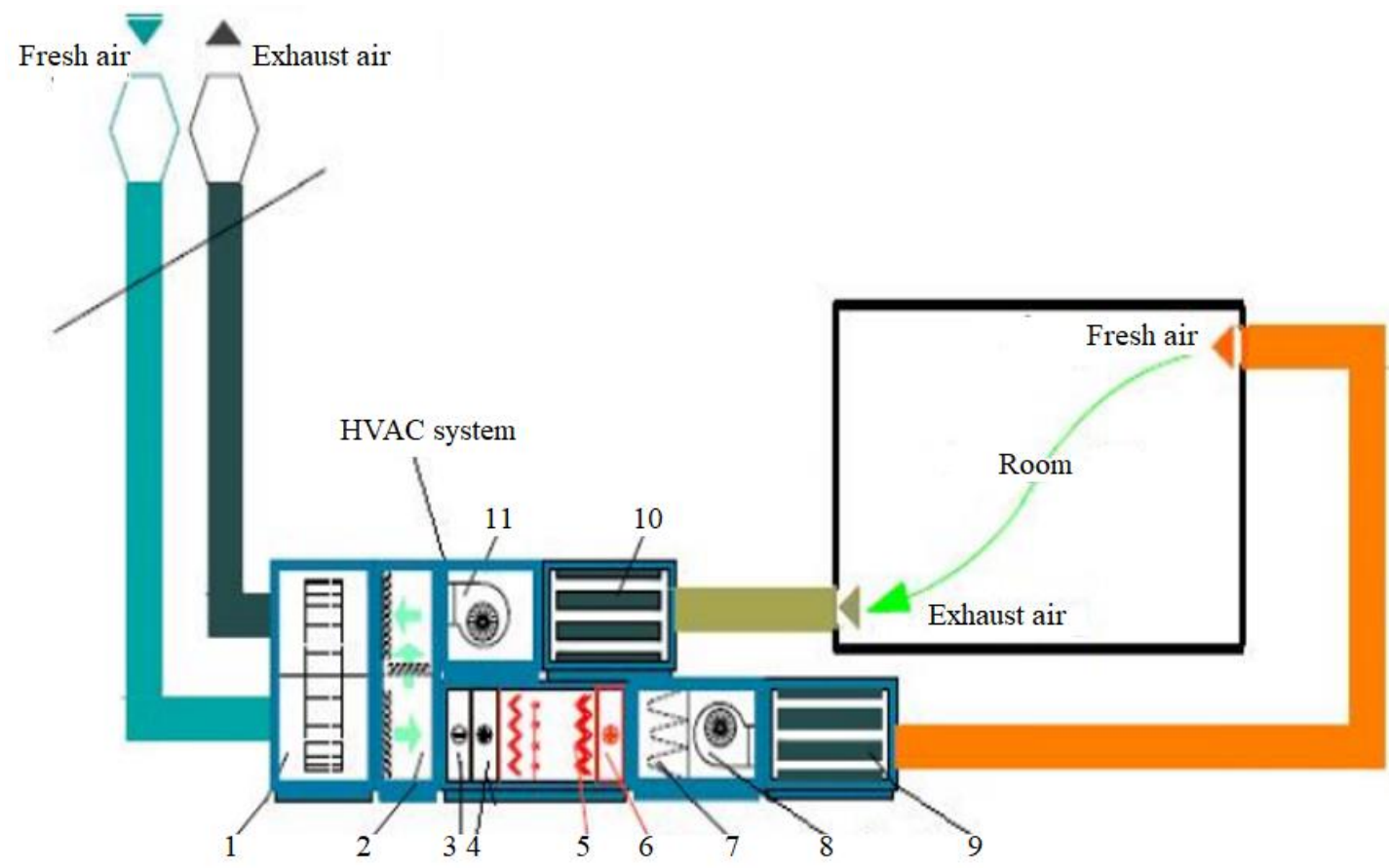

Fig. 2. Structure of a heating, ventilation and air conditioning system: 1- heat recuperated; 2- air recirculation module; 3- refrigeration module; 4, 6heating module; 5- humidifier; 7- air filter; 8- suction fan; 9,10 - noise attenuators; 11- exhaust fan.

Primary fluids (such as air or water) are prepared in centralized equipment that is usually located in the engine room (in the case of large installations and large powers). The terminal equipment is always installed in the places / areas of occupation of the hall, receives the fluids (already prepared in centralized equipment) and uses them to discharge the treated air in the necessary areas [6], [7], (fig.1).

Between the centralized equipment and the terminal equipment, the primary fluids and the treated air are distributed through pipes that provide many accessories necessary for a good operation (dampers, filters, valves, etc.). In addition, the installations are equipped with control and safety devices (thermostat, pressure switches, fire detectors) that are controlled by centralized computing units (for example: high-performance control systems, which is in fact the object of this work) [8].

The central control unit-CCU takes the information from the sensor on the temperature and humidity in the air-conditioned enclosure and processes it (fig. 3). After processing this information, the control module receives a electrical signals and transmits the control of the execution elements of the air conditioning unit (compressor, heating element, humidifier pump, fan) [9].

The sensor reads the temperature and humidity in the air-conditioned enclosure in real time and transmits this information to the CCU.

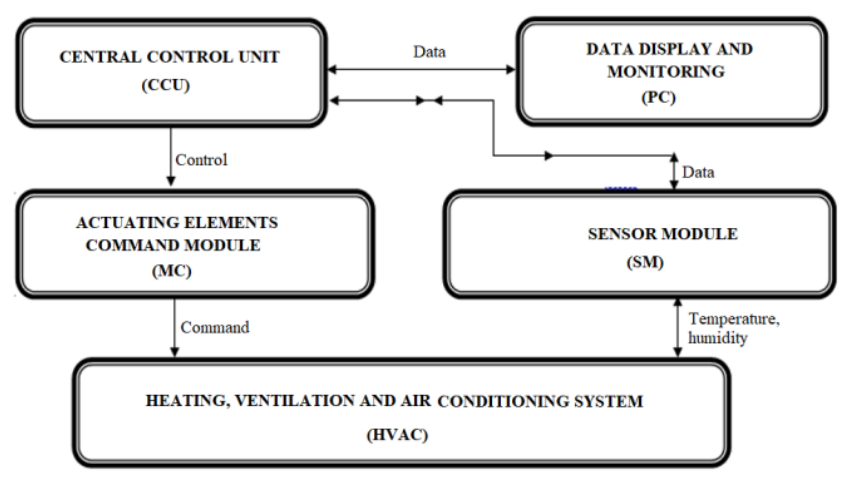

Fig. 3. Block diagram of a command and control system

The air conditioning unit has 3 operating modes: cooling, heating, humidification or dehumidification depending on the settings received from the command and control unit but also from the information transmitted by the sensor [10].

All collected data will be viewed in real time using a mobile device or a computer that constantly communicates with the control unit.

\section{IMPLEMENTATION OF SMALL SCALE MODEL OF} HEATING VENTILATION AND AIR CONDITIONING SySTEM

Based on the real model system, a small-scale model was developed for the heating, ventilation and air conditioning system (HVAC) [4]. 
The whole air conditioning system is structured and composed of three subassemblies:

1) Air conditioning system (The power part of the system).

2) Electrical installation;

3) Control system.

Figure 4 shows the model of the HVAC system made.

According to figure 4 , the realized physical model consists of:

- air conditioning unit - it contains: compressor, fancondenser assembly, evaporator (cooling battery), fan for introducing air into the enclosure, heating elements;

- the enclosure where the air conditioning is performed: it was made of hobby glass (transparent material);

- the housing in which the cooling / heating battery is inserted: it was also made of a transparent material, in order to be able to observe the construction of the component elements

- evaporator (cooling battery);

- electrical resistors used for the heating process;

- humidifier;

- piping for introducing air conditioning into the enclosure;

- piping for air recirculation;

- piping for introducing the air subjected to the humidification process;

- recirculation valve;

- temperature and humidity sensor;

- control panel;

- the electrical part of the installation (contactor, automatic fuses, connectors).

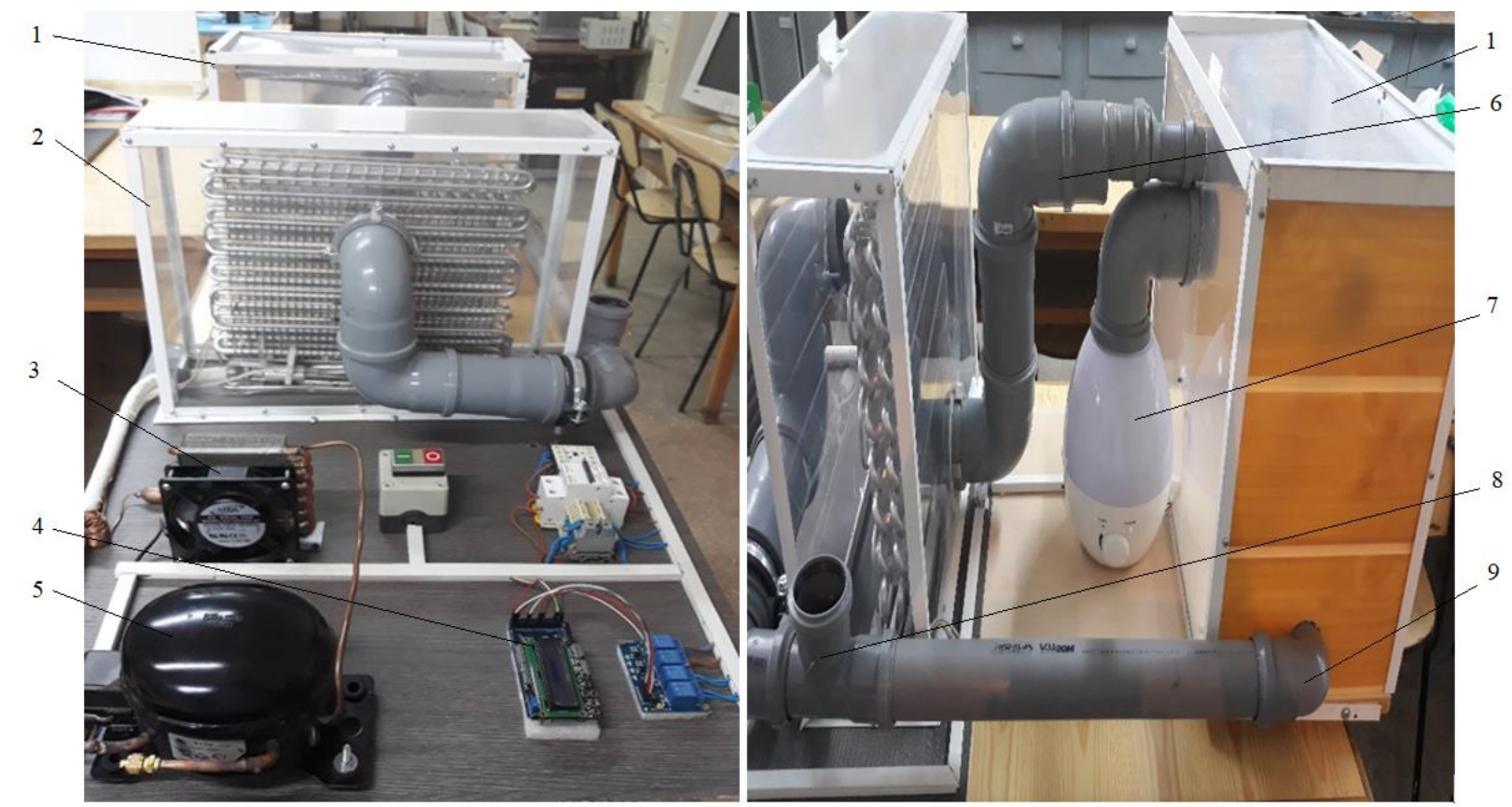

Fig. 4. HVAC system achieved:1- air-conditioned enclosure; 2- heating/refrigeration module ; 3- heat exchanger (condenser); 4-control module; 5compressor; 6- supply air duct; 7- humidifier; 8- flap of air mixed ; 9- exhaust air duct

\section{A. Achieved of local control system}

In order to be brought to the parameters with which it can be introduced in the space where air conditioning is required, the air undergoes a succession of elementary transformations. These parameters are controlled by means of a Mega2560 development board, which processes the information received from the DHT22 temperature and humidity sensor. Then, the physical components of the command and control circuit of the installation are presented together with the electrical connection diagram [11].

Mega 2560 is a development system built around the Atmega2560 microcontroller which is provided with numerous communication pins, analog and PWM useful for connecting with various elements: monitoring, command, control, etc. (sensors, relays).

Technical specifications of the development system are presented in the product catalog sheet [12].
For the control of the actuating elements, a compact board with 4 relays was used, having the following characteristics:

Voltage: 250VAC or 30VDC

Current: 10A (Max)

Each relay is controlled by an optocoupler

Optocoupler supply voltage: $5 \mathrm{~V}$

Current required for control: $5 \mathrm{~mA}$

The DHT22 sensor was used to measure temperature and humidity, having the following characteristics:

Supply voltage: 3.3 - 6V DC

Operating plate: temperatures -40 and $80^{\circ} \mathrm{C}$

Reading time: $2 \mathrm{~s}$

Humidity range: $0-100 \% \mathrm{RH}$

Accuracy: $\pm 0.5^{\circ} \mathrm{C}$

Wiring diagram for connecting of control elements are shown in figure 5 . 


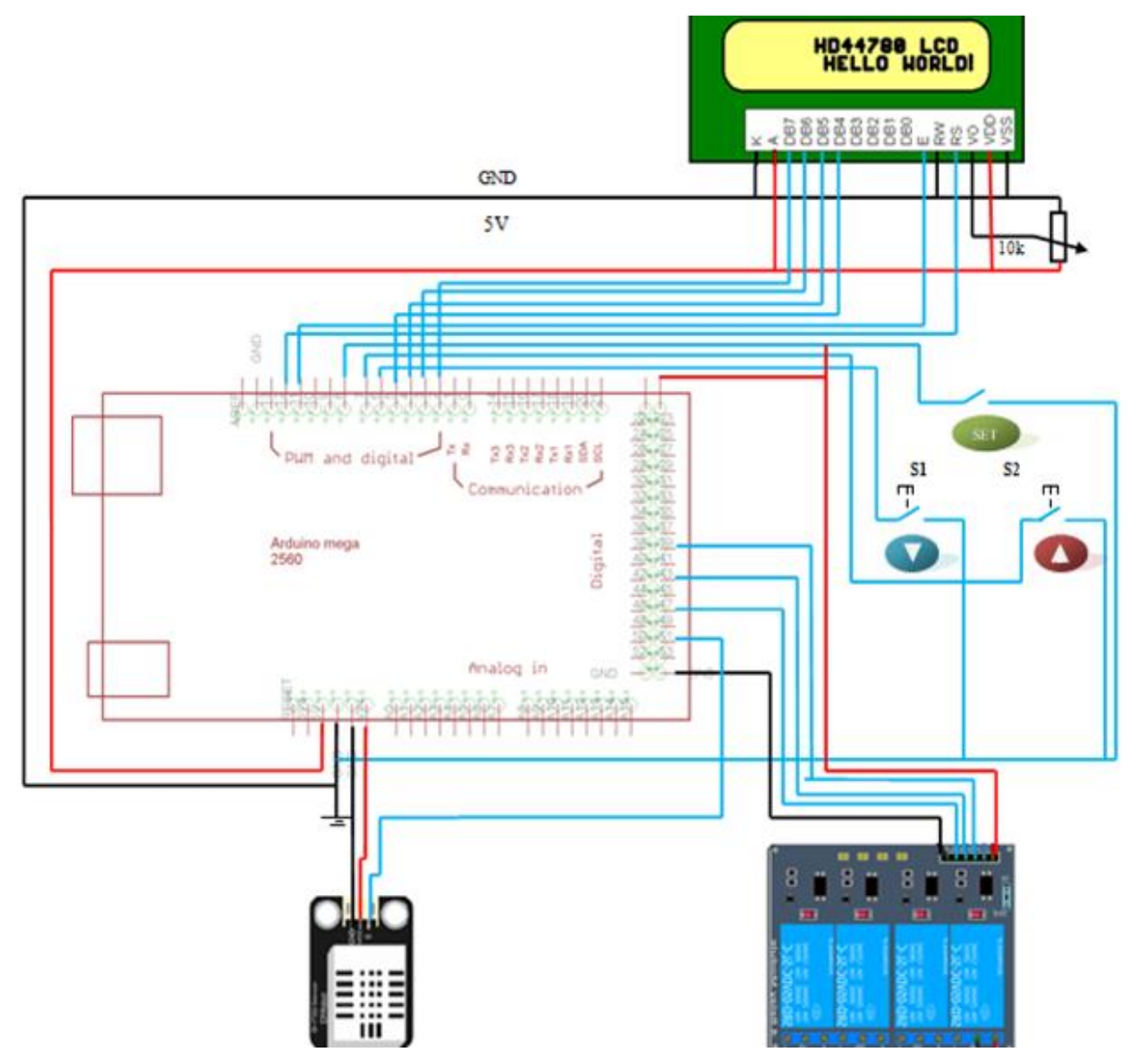

Fig. 5. Wiring diagram of local control system

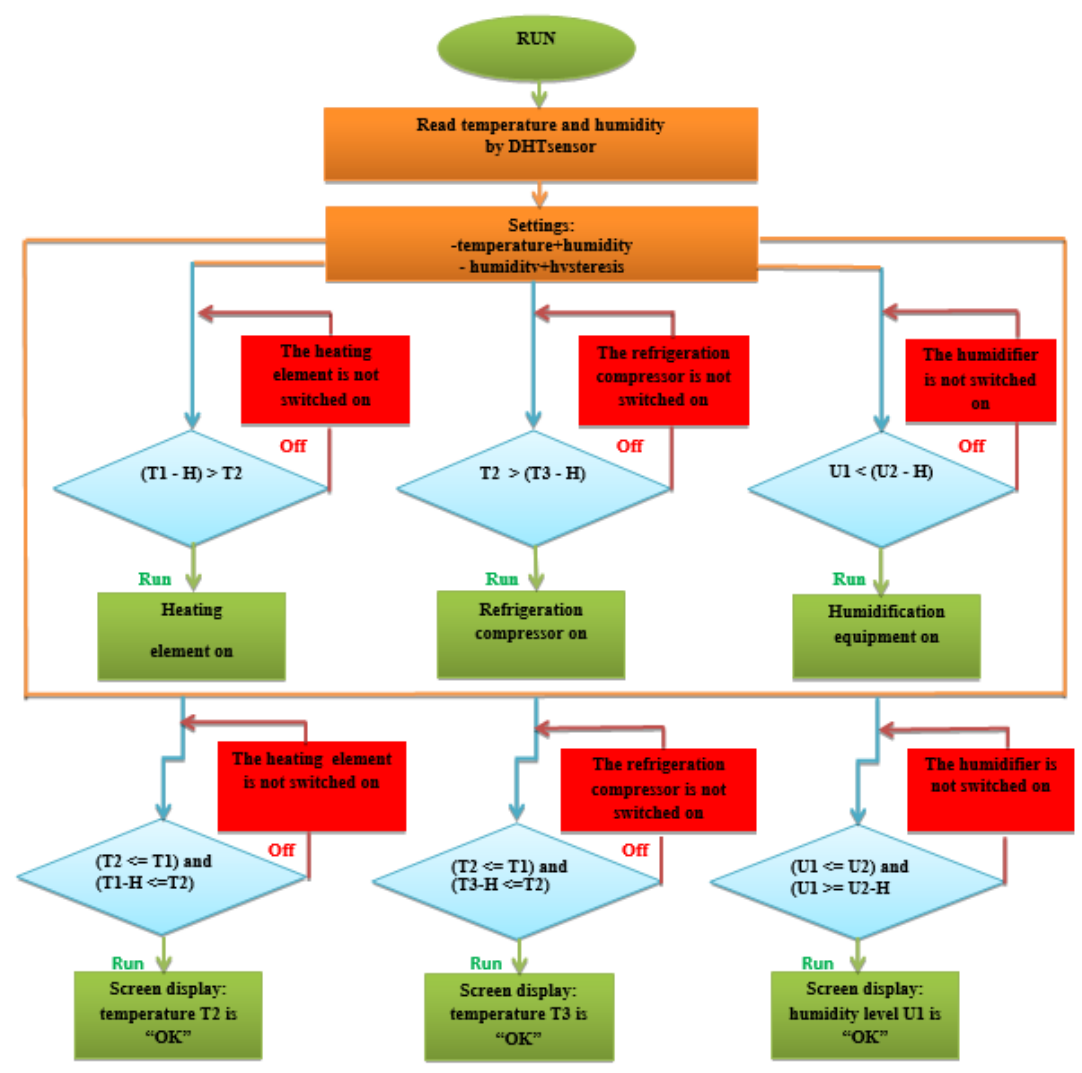

Fig. 6. Flowchart of control system 
The software part of the platform is integrated in an IDE graphical interface, based on the Processing programming language. Programming the controller on the physical platform is done using the Arduino programming language.

The Arduino integrated development environment is designed to write programs that can be loaded onto physical Arduino platforms. The interface is written in Java and the programming environment uses open source programming languages such as Processing, AVR-GCC [13].

The mode of operation of the development board is presented in the form of a flowchart (Fig. 6) and the program code.

\section{B. Achieved of remote control system}

The WeMos D1 R2 WiFi development system based on an ESP8266 wireless microcontroller with Wi-Fi 802.11 compatible with the IDE-Arduino development environment is used for the remote control [14]. The structure of this board is based on a standard Arduino hardware design with similar proportions to Arduino Uno and Leonardo.

The CH340 USB interface allows it to be connected and programmed directly from the computer and requires only a micro USB communication and power cable.

The system can be accessed remotely via the Cayenne online platform based on a name, a user password and a customer ID [15]. The connection data on the platform together with the user data and password of the wireless router are added in the source program written in Arduino Ide.

Wiring diagram for connecting of control elements are shown in figure 7.

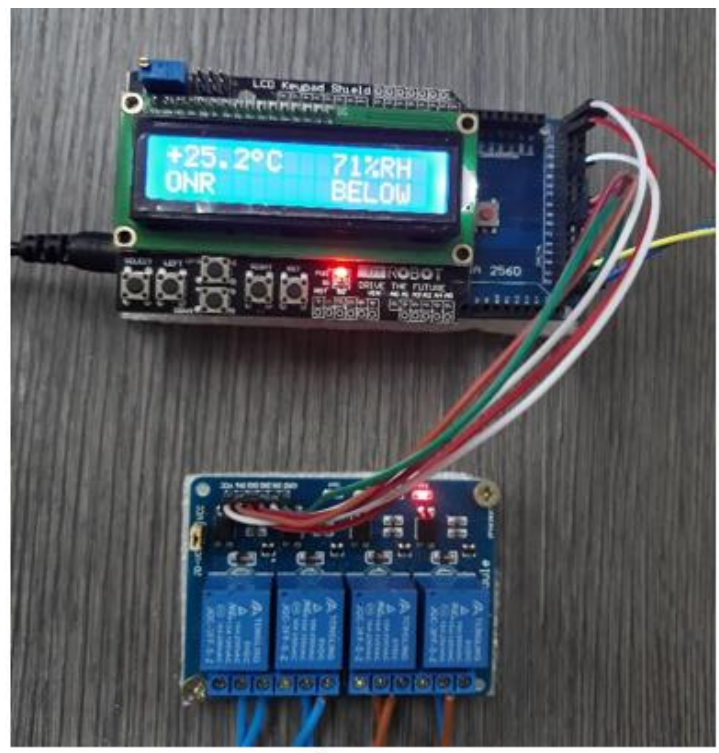

a)

Fig. 8. Testing in cooling mode

For operation in cooling mode, the desired temperature is selected from the development system menu, for example: $23{ }^{\circ} \mathrm{C}$. Then it is observed (fig. 8.b) the activation of the "In2" input of the relay that shows the operation of the compressor (red LED is OFF). The

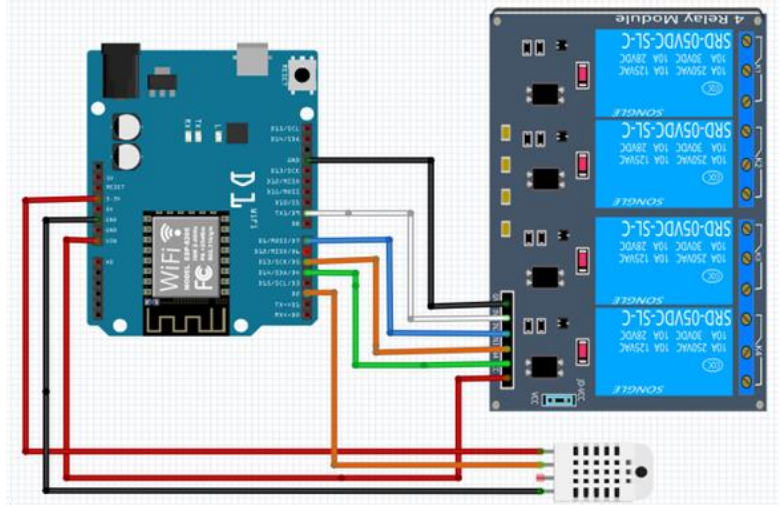

Fig. 7. Wiring diagram of remote control system

The main advantage of this system is given by the multitude of analog and digital outputs that are arranged on the same board but also by the technical characteristics.

\section{Testing Of HVac System}

\section{A. Testing of local control system}

In order to highlight the functionality of the experimental model, a series of tests were performed, in which all three modes of operation of the installation were captured in the form of images: cooling, heating, humidification.

\section{Testing of HVAC system in cooling mode}

In this case, when the system is started, the initial parameters are displayed on the screen: temperature and humidity (fig. 8. a). It can be seen from the figure that the temperature inside the enclosure at that moment is 25.2 ${ }^{\circ} \mathrm{C}$.

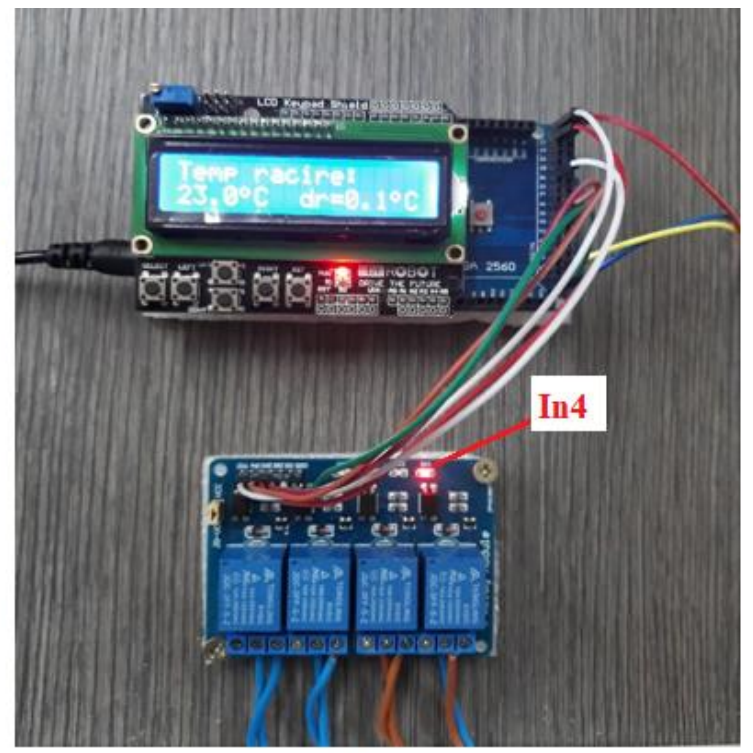

b)

compressor will operate without interruption, until the desired temperature is reached, at which point the "In2" input of the relay will receive the compressor switch-off command (red LED is ON). 


\section{Testing of HVAC system in heating mode}

Proceed identically to the case described above, namely:

- at the start of the system, the real parameters of the enclosure are displayed on the screen;

- it is observed from figure 9. a) that the temperature inside the enclosure at that moment is $24.6^{\circ} \mathrm{C}$;
- for the selected operating mode, the indoor air heating mode, the temperature of $25.2^{\circ} \mathrm{C}$ is chosen from the system menu (fig. 9. b);

- the heating elements are controlled at this moment by activating the "In1" input of the relay (red LED is OFF);

- they operate without interruption until the desired temperature is reached (fig. $9 \mathrm{c}$ ), at which point the "In1" input of the relay will receive the command to disconnect the resistors (red LED is ON).

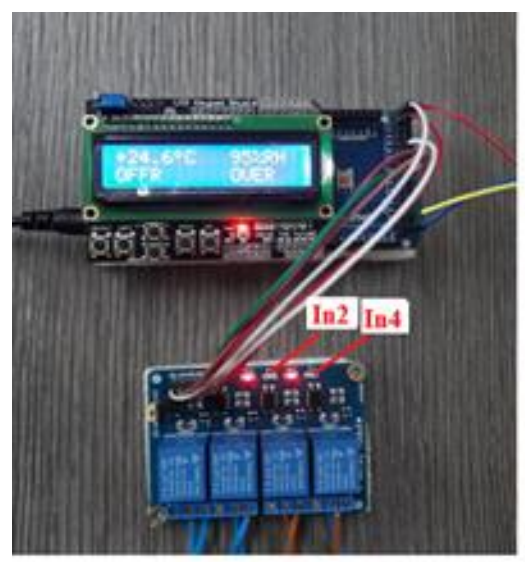

a)

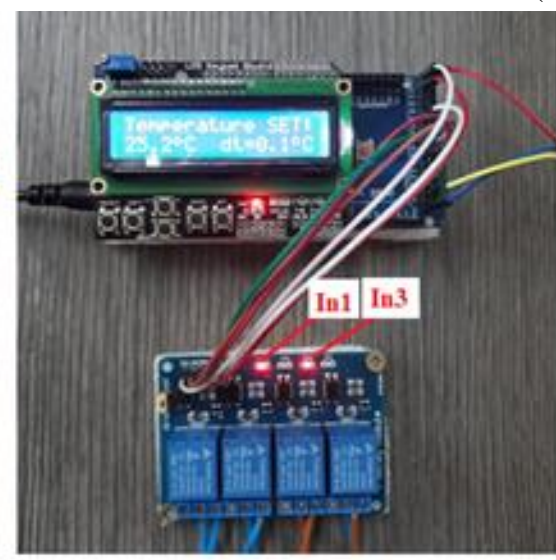

b)

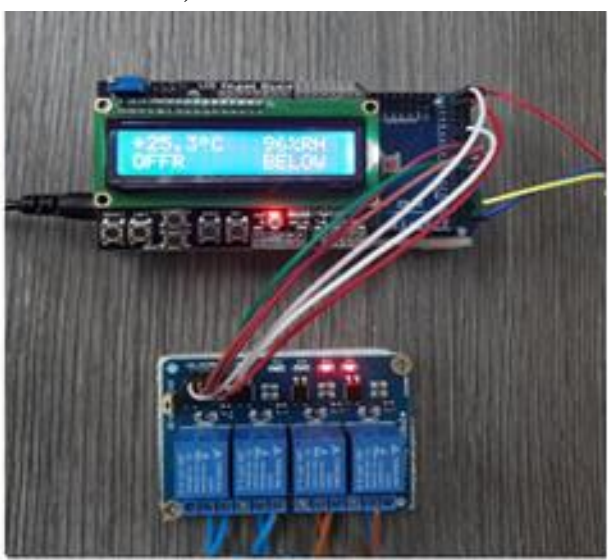

c)

Fig. 9. Testing in heating mode

\section{Testing of HVAC system in humidity mode}

The same procedure is followed for this mode of operation of the installation:

- at the start of the system, the real parameters of the enclosure are displayed on the screen;

- it is observed from figure 10.a) that the humidity inside the enclosure at that moment is $95 \%$;

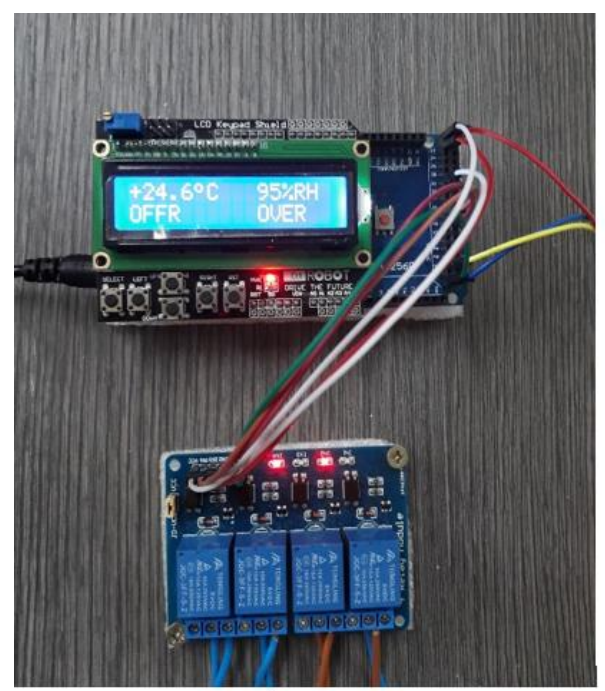

a)

Fig. 10. Testing in humidity mode

\section{B. Testing of remote control system}

The verification of the operation of the system was performed through a series of tests, in which all the modes of operation of the installation were captured.
- for the chosen operating mode, the humidification of the indoor air, the value for humidity of $99 \%$ is chosen from the system menu;

- the humidifier is currently controlled by activating the "In4" input of the relay (red LED is OFF), (fig 10 a);

- it works without interruption until the desired value is reached, at which point the "In4" input of the relay will receive the humidifier switch-off command (red LED is $\mathrm{ON}$ ), (fig. $10 \mathrm{~b}$ ).

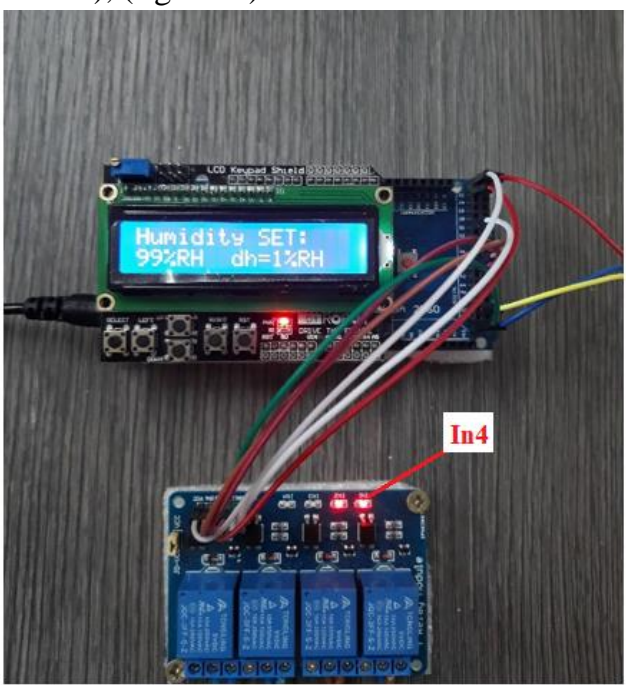

b)

All information taken from the air-conditioned room is transmitted wirelessly to an online platform that allows their storage and control (figure 11). The platform referred to is called Cayenne and offers a number of graphical features that do not involve costs for users. 


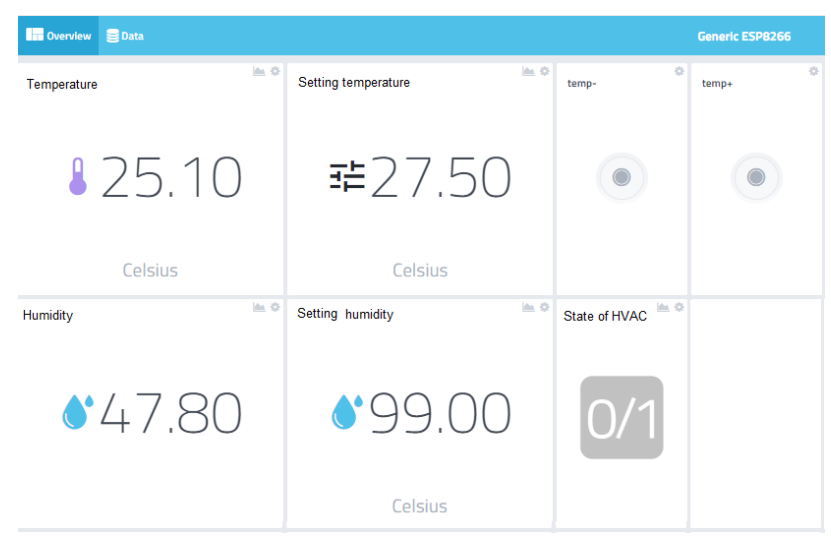

Fig. 11. Panel of remote control system

The simulation of the implemented system operation can be easily followed on the Cayenne platform, and the evolution of the parameters can be observed graphically over different periods of time or in real time, analyzing the operation graphs at the desired intervals.

According to those specified, simulations were performed for the 3 operating modes of the plant: cooling, heating, humidification.

\section{Testing of remote control system in cooling mode}

Figure 12 shows the operation of the HVAC system in cooling mode, when the compressor is controlled by the In1 input of the relay (red LED off), the temperature tends to gradually decrease to the prescribed value in the control panel of $22.0^{\circ} \mathrm{C}$.

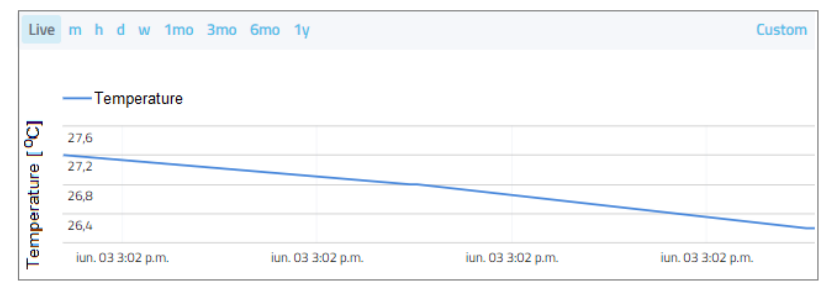

Fig.12 Evolution of the room temperature: mode of operation - cooling

\section{Testing of remote control system in heating mode}

After setting the desired temperature, the In 2 input of the relay will be activated, which will control the heating elements and the system will start in heating mode. The graph in figure 13, shows the operation of the system and the ascending slope that tends to reach the value of the room temperature.

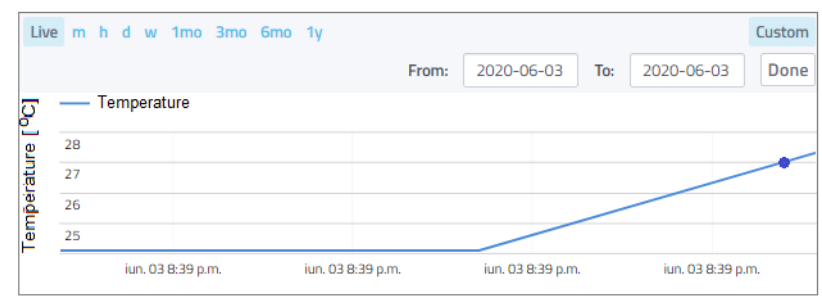

Fig.13. Evolution of the room temperature: mode of operation - heating

\section{Testing of remote control system in humidity mode}

The control principle of the installation in this mode of operation is similar to those presented above, except that the measured humidity will be compared with the set one. The set humidity value is $99 \%$. With the entry into operation of the humidifier, the increase of humidity towards the maximum set value of $99 \%$ is observed (figure 14).

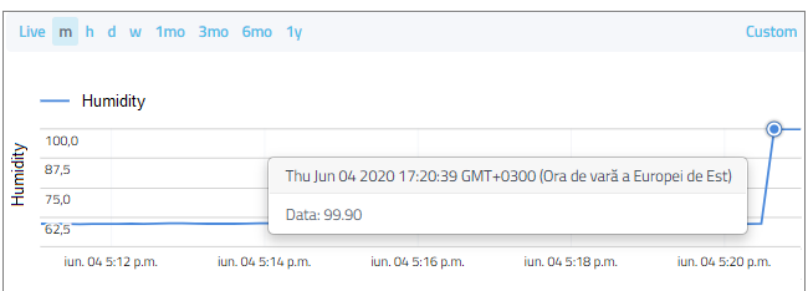

Fig.14. Evolution of the room humity: mode of operation - humidity

Having the same principle of operation, the installation also operates in this case without interruption until it reaches the prescribed value, at which point the microcontroller sends a pulse to the relay which is set to control the deactivation of the humidifier (In3 - red LED off).

\section{CONCLUSION}

The correct operation of the system in the three modes of operation (heating, cooling, and humidification) is highlighted in the experimental results.

Both the control part and the execution elements are different from those of a real HVAC system. The experimental model performs the same functions as a real system.

Considering these aspects and the low price of the system components, the possibility of use in civil or industrial applications can be analyzed.

The system designed, developed and tested can be used both in educational applications in electrical engineering and in industrial applications.

\section{ACKNOWLEDGMENT}

Source of research funding in this article: Research program of the Electrical Engineering Department financed by the University of Craiova.

Contribution of authors:

First author $-60 \%$

First coauthor $-40 \%$

Received on July 17, 2021

Editorial Approval on November 30, 2021

\section{REFERENCES}

[1] *** Technical Encyclopedia of Installations, Installation Manual: Heating Installations, 2nd edition, Ed. Artecno Bucharest, 2010.

[2] *** Technical Encyclopedia of Installations, Installation Manual: Ventilation and Air Conditioning Installations 2nd Edition, Ed. Artecno Bucharest, 2010. 
[3] S. Mahlangu, M. Sibanyoni; L. Ngoma, S. Chowdhury, "The Design of HVAC Network Control Panel For Battery Room", 2020 6th IEEE International Energy Conference (ENERGYCon), 28 Sept.-1 Oct. 2020, Gammarth, Tunisia.

[4] L. Alboteanu, C. Militaru, "Small Scale Model of Heating, Ventilation and Air Conditioning System", 2021 International Conference on Applied and Theoretical Electricity (ICATE), 27-29 May 2021, Craiova, Romania.

[5] L. Alboteanu, Air conditioning installations, Ed.Universitaria, Craiova, 2012.

[6] *** Norm for the design, execution and operation of ventilation and air conditioning installations, indicative I5 /2010.

[7] ANSI/AHRI Standard 210/240 with Addenda 1and 2 (Formerly ARI Standard 210/240), Performance Rating of Unitary AirConditioning \& Air-Source Heat Pump Equipment.

[8] H. Jouhara, Y. Junjing, " Energy efficient HVAC systems", Energy and Buildings, Volume 179, pp. 83-85, 15 November 2018.
[9] J. D. Kelso, Building Energy Data Book, 2012.

[10]F. Belic, Z. Hocenski, D. Sliskovic, "HVAC Control Methods - A review", Procc. Of 19th International Conference on System Theory, Control and Computing (ICSTCC), October 14-16, Cheile Gradistei, Romania, 2015.

[11]L. Alboteanu, Manolea Gh., Ravigan F., "Automatic sorting and handling station actuated by pneumatic drive" Annals of the University of Craiova, Electrical Engineering Series, no 1, 2018, ISSN 1842-4805, pp.1-8.

[12]*** http://www.atmel.com

$[13]^{* * * *}$ https://www.arduino.cc/

[14] ***https://www.instructables.com/Programming-the-WeMosUsing-Arduino-SoftwareIDE/

[15] *** https://developers.mydevices.com/cayenne/features/remotemonitoring/ 